\title{
A cross-modal effect of noise: the disappearance of the alarm reaction of a freshwater fish
}

Md Robiul Hasan ${ }^{1}$, Adam L. Crane ${ }^{1}$, Maud C. O. Ferrari ${ }^{2}$ and Douglas P. Chivers ${ }^{1}$

${ }^{1}$ Department of Biology, University of Saskatchewan, Saskatoon, SK, Canada

${ }^{2}$ Department of Biomedical Sciences, WCVM, University of Saskatchewan, SK, Canada

Author for correspondence: adam.crane@ usask.ca

Short title: Noise and alarm cues

\begin{abstract}
Anthropogenic noise pollution is recognized as a major global stressor of animals. While many studies have assessed the unimodal impacts of noise pollution with a focus on intraspecific acoustic communication, little is known about noise pollution on the perception of visual and chemical information. The 'distracted prey hypothesis' posits that processing noise interferes with processing other information in the brain. Here, we found evidence for such a cross-modal effect of noise on the antipredator behaviour of a freshwater prey fish, the fathead minnow, Pimephales promelas. In laboratory trials, exposure to noise from a motorboat caused the total absence of the classical fright reaction of minnows to conspecific alarm cues, whereas an ambient noise control had no such impact. In natural habitats, the impairment of such antipredator behaviour due to noise pollution could have major fitness consequences. We discuss how our findings translate to animal ecology and the need for future studies that target specific management decisions regarding noise pollution.
\end{abstract}

Keywords: alarm cues, anthropogenic noise, antipredator behaviour, boat noise, predation risk 


\section{Introduction}

The acoustic environment is critically important to animal cognition and communication (Halfwerk and Slabbekoorn 2015; Pijanowski et al. 2011). Natural sounds result from geophysical motion of the atmosphere and water (e.g., river flow, rain), and are produced by a wide range of animal species from their movement and in their communication of food, courtship, territories, or predators (Brumm 2013). However, over recent decades, noise pollution has been increasing at an unprecedented rate due to anthropogenic activities such as increased transportation networks (e.g., road traffic), energy exploration (e.g., seismic surveys), construction (e.g., pile driving), and recreation (e.g., boating) (Graham and Cooke 2008; Hildebrand 2009; McDonald et al. 2006; Shannon et al. 2016).

Negative impacts on animal cognition and ecology can occur when anthropogenic noise overlaps with the sensitive hearing ranges of animals. For instance, noise can mask the acoustic signals and cues that are used by animals during communication (e.g., Templeton et al. 2016). In other cases, animals may adjust the frequencies of their vocal signals to prevent overlap with anthropogenic noises (Cunnington and Fahrig 2010; Halfwerk and Slabbekoorn 2009). Such effects have been categorized as unimodal sensory effects because they occur within the same sensory domain, in this case the auditory domain. However, cross-modal sensory effects (i.e., on information use via other sensory modalities) have also been documented in response to anthropogenic noise (Halfwerk and Slabbekoorn 2015). For example, common cuttlefish, Sepia officinalis, alter their use of complex visual signals in the presence of ship noise (Kunc et al. 2014). This outcome is consistent with the 'distracted prey hypothesis' which posits that processing noise interferes with processing other information in the brain (Chan et al. 2010). In that study, hermit crabs, Coenobita clypeatus, exposed to anthropogenic noise displayed slower reactions to visual cues of an approaching predator.

Predator avoidance is a fundamental aspect of animal behaviour and ecology. Assessing local predation risk and responding correctly is critical for the survival of prey species (Lima and Dill 1990). Some species manage predation risk by changing their morphology or altering the timing of life-history transitions (Relyea 2002), and behavioural defences are widespread, being rapidly enacted in response to acute threats. Such behavioural responses are fine-tuned to match the level of perceived threat (i.e., threat-sensitive responses: Helfman 1989), allowing prey to maximize the cost-benefit trade-off associated with under- or over-responding to risk (Ferrari et al. 2009). A few studies have documented altered antipredator behaviour in aquatic systems in the presence of anthropomorphic noise, primarily focussing on noise from motorboats (hereafter, boats). European eels, Anguilla anguilla, and ambon damselfish, Pomacentrus amboinensis, both exhibited flawed escape responses to predator visual stimuli in the presence of boat noise (Simpson et al. 2015; Simpson et al. 2016a). In another study, three-spined stickleback, Gasterosteus aculeatus, reacted more quickly to a predator visual stimulus, suggesting increased 
alertness rather than interference under boat noise conditions (Voellmy et al. 2014). Common minnows, Phoxinus phoxinus, in that study showed no change in reaction time to the visual threat, revealing interspecific differences in the influence of noise.

For many species, olfactory perception is essential for the recognition of predation threats, and in some cases more important than visual perception (e.g., at night or in turbid environments) (Mathis and Crane 2017). Many species recognize chemical odours from predators via urine, feces, or skin mucus. Moreover, many species recognize chemical cues that are associated with a predator attack. For instance, many fish species possess a chemical substance contained in their skin, originally described as 'Schreckstoff' (von Frisch 1938), that is released upon physical damage from a predator. This substance functions as an 'alarm cue' that elicits fright reactions in nearby individuals (Ferrari et al. 2010). In response to alarm cues, fathead minnows, Pimephales promelas, for example, show characteristic dashing and freezing behaviour, overall lower activity levels, and increased refuge use (Chivers and Smith 1993; Smith 1992). Minnows can also use such experiences to learn to recognize the identity of novel predators and types of habitats that are dangerous (Chivers and Smith 1994; Chivers and Smith 1995).

In contrast to visual perception, the cross-modal effects of noise on olfactory perception have received little attention. We are aware of only one study that evaluated such. In that study, dwarf mongooses, Helogale parvula, exposed to road noise failed to correctly detect olfactory cues from faeces of their predators (Morris-Drake et al. 2016). Here, our goal, was to explore the cross-modal effect of anthropogenic noise on the olfactory perception of predation risk by fathead minnows, Pimephales promelas. We tested whether anthropogenic noise from a boat influences the responses of minnows to alarm cues. As found in previous studies (e.g., Purser and Radford 2011; Wisenden et al. 2008), we expected the addition of underwater boat noise to elicit only a weak or negligible fright response in the absence of predation risk. However, we predicted that such noise can act as a stressor that interferes with olfactory perception and leads to weakened fright reactions toward alarm cues.

\section{Methods}

\section{Ethical note}

This work was conducted in accordance with the University of Saskatchewan's University Committee on Animal Care and Supply (protocol 20160058). We collected minnows under a Saskatchewan Ministry of Environment Special Collection Permit (SCP17-AR03). We followed a standard methodology for making alarm cues (Ferrari et al. 2010), using a blow to the head in accordance with the Canadian Council on Animal Care. All fish in this study either remain in our laboratory stock colony or have been euthanized with an overdose of tricaine methanesulfonate (MS-222). 
Minnow collection and maintenance

Approximately 200 minnows (unsexed; total length: 20-40 mm) were collected from Pike Lake in central Saskatchewan in July 2017. Minnows were transported to our laboratory and housed for $\sim 6$ months in a $\sim 2000$ L flow-through stock tank filled with filtered municipal water (hereafter, water) that received aeration via a hose with an airstone. The pool was maintained at $19^{\circ} \mathrm{C}$ under a 15:9 h light:dark cycle, and minnows were fed flake food daily. In preparation of the experiment, minnows were transferred in groups of 10-12 into 371 tanks in an experimental room. The tanks provided gravel substrate, shelter $(\mathrm{a} 10 \times 10 \mathrm{~cm}$ ceramic tile with $2-\mathrm{cm}$ PVC legs), over-head lighting, and a daily $30 \%$ water change.

\section{Alarm cues}

We sacrificed four individuals (23-35 mm total length) to make alarm cues. A total of 6.15 $\mathrm{cm}^{2}$ of skin was removed, homogenized (polytron PT-2500E) in water, and diluted to reach an established concentration of $1 \mathrm{~cm}^{2}$ of skin per 401 that is known to elicit a strong fright reaction (Ferrari et al. 2005). The alarm cue solution was then frozen at $-20^{\circ} \mathrm{C}$ in $100 \mathrm{ml}$ aliquots until being thawed before use.

\section{Field recordings and playbacks}

We recorded ambient and boat noise within Blackstrap Lake, Saskatchewan, using an omnidirectional hydrophone (CR1, calibrated sensitivity $-198 \mathrm{~dB}$ re $1 \mathrm{~V} / \mu \mathrm{Pa}$; frequency $0.02-$ $20 \mathrm{kHz}$; Cetacean Research Technology, Seattle WA) with a data-acquisition card (SpectraDAQ200). For boat noise, we recorded the sound of a Honda flat bottom John boat (5-m aluminum, 10 metric hp, and 4-stroke engine) passing from a distance of $10 \mathrm{~m}$ at $\sim 10 \mathrm{~km} / \mathrm{h}$ and 3-m depth. Our interest was in studying cross-modal effects and hence chose to use a single auditory stimulus to ensure a consistent stimulus. We also recorded the ambient lake noise as a control. In the laboratory, we used an underwater speaker (ECOXGEAR EcoRox) to play both sounds into the centre of experimental tanks (details below) and re-recorded the sound pressure with the hydrophone (6 cm from the speaker) and adjusted the intensity to match that of the field using SpectraPLUS (FFT size of 8192 points, Hanning window). Fish perceive sound as both pressure fluctuations and particle motion (Rogers et al. 2016). Here, we quantified differences between our ambient and boat noise treatments by comparing sound pressure spectrums, although we were unable to compare particle motion. Based on previous research on auditory brainstem responses, frequencies of $1-2 \mathrm{kHz}$ are viewed as the most sensitive hearing range for minnows (Scholik and Yan 2002). Within this range, boat and ambient noise playbacks were slightly higher in sound pressure compared to their respective sounds in the field, with the boat noise being roughly $35 \mathrm{~dB}$ higher in intensity than the ambient noise (Fig. 1a). We also recorded the 
baseline level of noise (i.e., no playback) in the centre of an experimental tank and the stock tank, which appeared to be fairly consistent in intensity with our re-recording of ambient playback in experimental tanks (Fig. 1b).
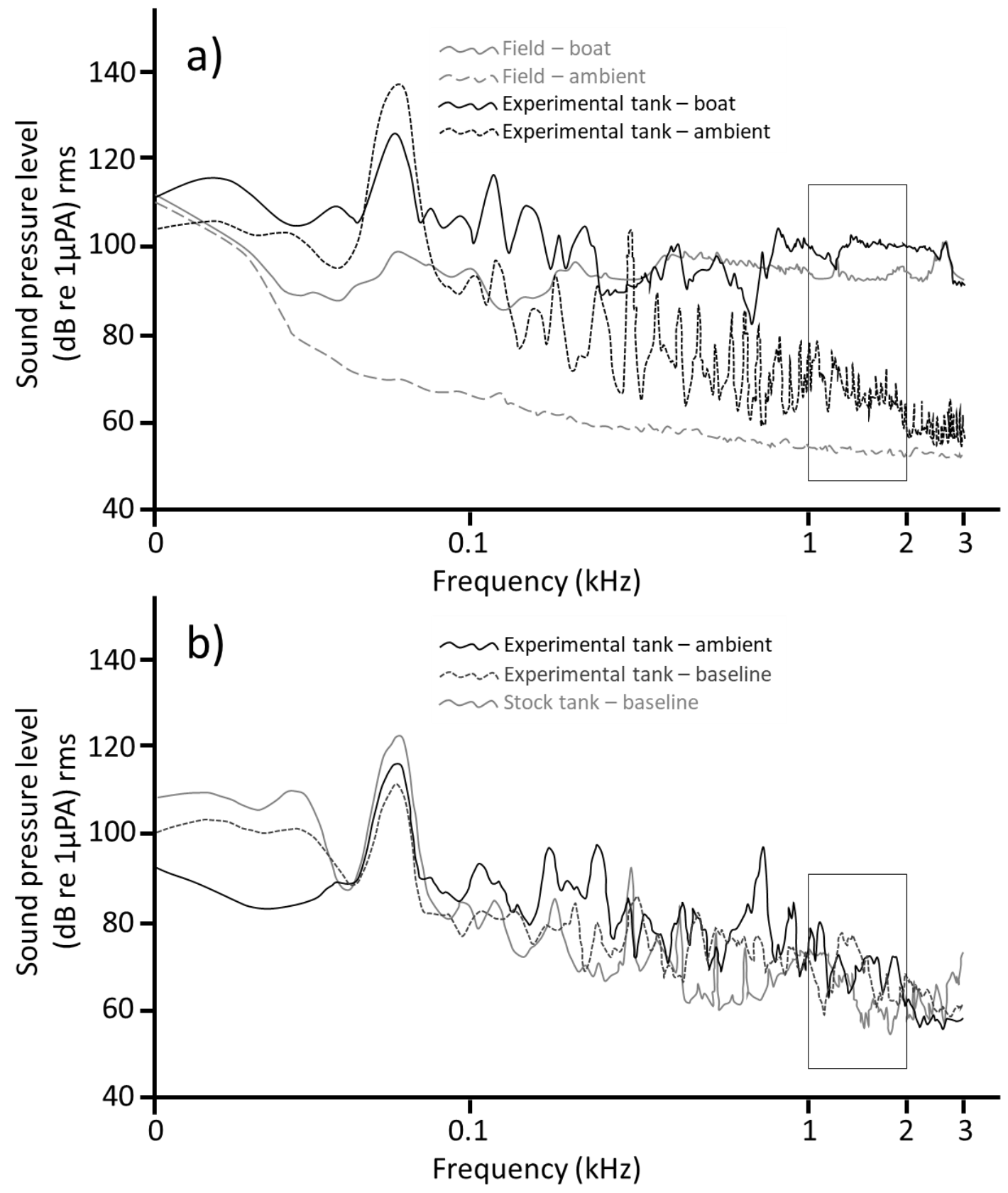

Figure 1. (a) Sound pressure levels ( $\mathrm{dB}$ re $1 \mu \mathrm{Pa}$ ) for ambient and boat noise at the field site and their re-recordings from playbacks in laboratory tanks. (b) Sound pressure levels for ambient noise playback (re-recording) and experimental and stock tank baselines (i.e., no playback). The thin rectangle encompassing 1-2 kHz represents the presumed, most sensitive hearing range of minnows (Scholik and Yan 2002). 


\section{Experimental protocol}

We used a $2 \times 2$ design where minnows were exposed to either distilled water (control) or alarm cues under conditions of either ambient or boat noise. After acclimating to the experimental room for at least 1-week, individual minnows were moved into separate 37-1 experimental tanks, again with gravel, shelter, lighting, aeration, and an underwater speaker. The front of each tank was covered with a plastic film (5\% visual light transmission), allowing us to observe the fish while minimizing visual cues from our presence. Fish were allowed to acclimate to the new tank for $24 \mathrm{~h}$ before observations were conducted. Each trial consisted of three parts: (1) an 8-min pre-stimulus period, (2) the onset of noise paired with a stimulus injection of either $20 \mathrm{ml}$ of alarm cues or water control, and then (3) an 8-min post-stimulus period. Each injection occurred gently through a hose attached to an airstone in the tank, while noise was initiated via a Bluetooth transmitter. The ambient noise treatment consisted of ambient noise playback for the full $8 \mathrm{~min}$, whereas the boat noise exposure consisted of $2 \mathrm{~min}$ of boat noise followed by $2 \mathrm{~min}$ of ambient noise and then alternated for the remaining time. During both the pre- and poststimulus periods, we calculated the number of lines that each minnow crossed on a grid $(6.3 \times 6.3$ $\mathrm{cm}$ ) and the time spent under shelter (converted to time in open; see below). Minnows were tested only once, and sample sizes were 26 per treatment group.

\section{Statistical analysis}

For both response variables, we calculated a proportional change [(post-stimulus - prestimulus)/pre-stimulus] to account for individual variation in pre-stimulus data. Doing such for time spent under shelter necessitated the conversion to time spent in the open (total trial time time spent under shelter) to eliminate zero values in the pre-stimulus data. We then analyzed differences in the two proportional responses using a 2-way MANOVA with the chemical cue (alarm cue or water) and the noise treatment (boat or ambient) as fixed factors. Because nonnormality and covariance heterogeneity assumptions were not fully met, we used Pillai's trace for its conservativeness (Olson 1976). In post-hoc analyses (1-way MANOVAs), data were split by noise treatment and the fish responses to alarm cue and water were compared.

\section{Results}

A significant interaction revealed that responses to alarm cues depended on the noise treatment (noise $\times$ chemical cue: $F_{2,99}=8.80, P<0.001$; Fig. 2 ). In comparison to the control, fright reactions to alarm cues were strong under ambient noise conditions $\left(F_{2,49}=19.74, P<\right.$ $0.001)$, but these responses were absent in the presence of boat noise $\left(F_{2,49}=0.07, P=0.93\right)$. 

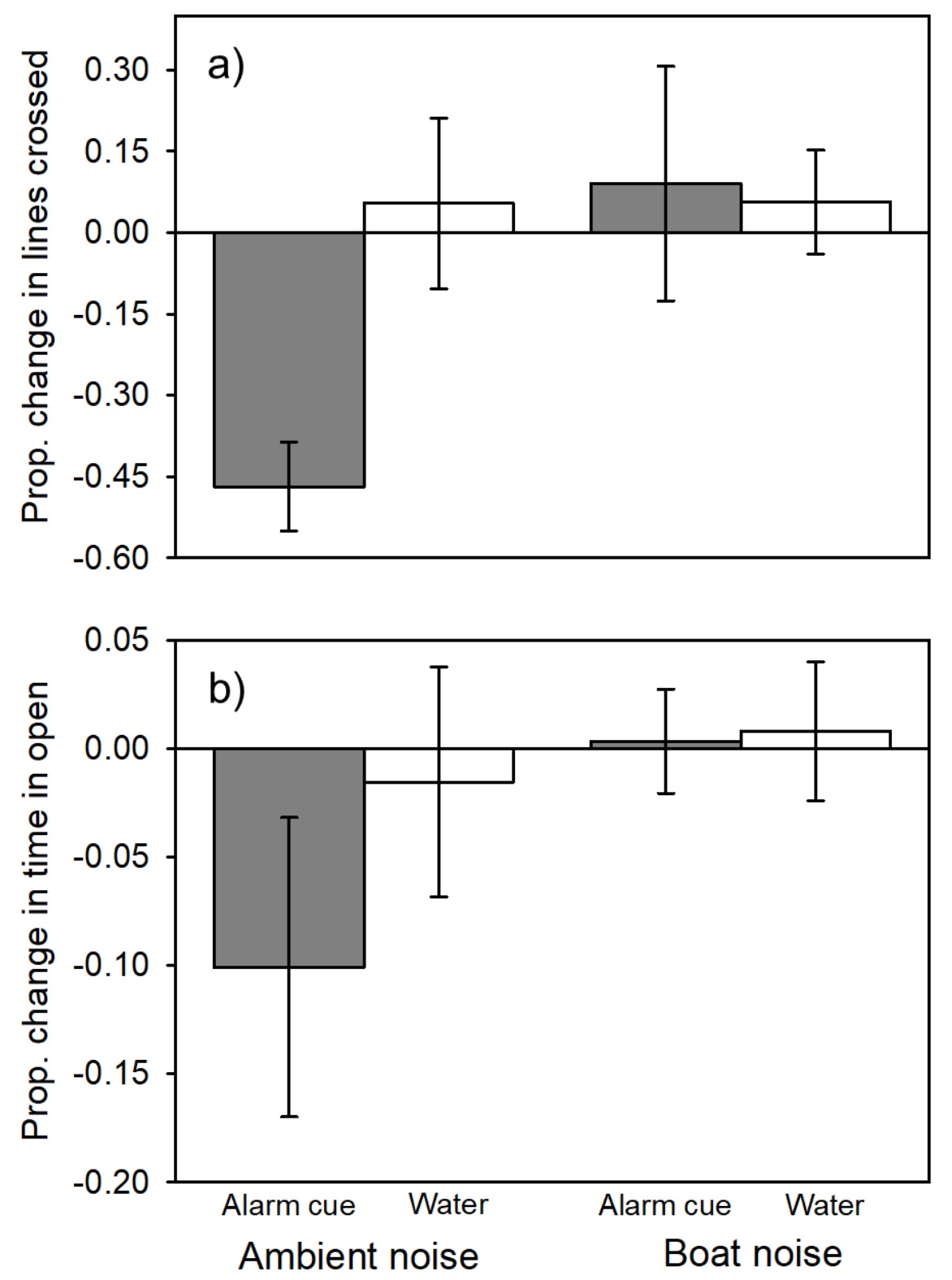

Figure 2. Mean ( $\pm 95 \% \mathrm{CI}$ ) proportional change in (a) lines crossed and (b) time in open for fathead minnows (Pimephales promelas) exposed to distilled water and alarm cue under either ambient or boat noise conditions.

\section{Discussion}

Our results add to the evidence for cross-modal effects of noise and are the first evidence for a cross-modal effect of noise on alarm cue olfaction. We considered possible mechanisms for such an outcome, first that our noise stimulus physically damaged the olfactory tissue. However, this seems unlikely given such a low intensity and such a short time frame of noise exposure. We 
are not aware of any studies that would indicate such. Alternatively, increased vigilance under noise conditions might explain the absence of a change in overall activity, but not the absence of a change in shelter use; under our experimental tank conditions, highly vigilant minnows move back and forth rapidly underneath shelter (personal observations). Another possibility is that noise caused an energetic loss either from increased metabolism or from foraging errors that promoted increased foraging behaviour (Halfwerk and Slabbekoorn 2015). The fish in our experiment did continue to search for food under noise conditions (personal observations), so we cannot discount this mechanism, although a biologically relevant energy loss again seems unlikely given the acute exposure.

Considering the lack of support for the aforementioned mechanisms, we view the most plausible explanation for our results as a limit in the cognitive attention or processing capacity (i.e., the distracted prey hypothesis) of minnows. An inability to simultaneously perceive both auditory and chemical stimuli would suggest that noise interferes with the processing of chemical information in the fish brain. Acoustic stimuli in fish are transferred to the telencephalic lobe in the forebrain, where the lateral and medial divisions of the pallium process both auditory and olfactory stimuli (Northcutt 2006). Thus, cross-modal interference could occur in this brain region. To our knowledge the molecular underpinnings of such an effect remain unexplored in fishes, but in rats, Rattus rattus, cognitive impairment from elevated noise appears mediated by disruption of a signaling receptor (glutamate-N-methyl-D-aspartic acid) that alters phosphorylation of a protein (tau) associated with cognitive deficits and neurodegeneration (Cui et al. 2012).

Correctly responding to alarm cues is crucial to many species for predator detection and learning, and thus both short- and long-term survival (Ferrari et al. 2010). Hence, this study may have important implications for fishes that are exposed to anthropogenic noise in their natural environments. However, we caution that results from studies on laboratory noise may not be comparable to field environments. Noise in the natural environment can differ substantially from noise playbacks in small tanks due to the particle motion reflecting off tank surfaces (Rogers et al. 2016), which we were not able to measure in this study. However, in a study by Simpson et al. (2016b), the survival of damselfish exposed to noise was similar under both laboratory and field conditions, indicating that the laboratory results were a good proxy for the field environment in that study. Those fish were a shallow water species living on shallow coral reefs, so perhaps results of laboratory sound are more translatable to shallow habitats such as those used by minnows. However, for deeper water species, laboratory results may not reflect field outcomes.

There is evidence that anthropogenic boat noise can have a variety of negative impacts on fishes, from altered movement patterns and poor habitat settlement, to decreased foraging efficiency, territorial defence, reproductive behaviour, and predator avoidance (Bracciali et al. 2012; Bruintjes and Radford 2013; Sarà et al. 2007; Sebastianutto et al. 2011; Simpson et al. 
2015; Simpson et al. 2016a). We still know little, however, about the severity and longevity of effects from boat noise, or the impact of boat noise in natural communities (e.g., noise can affect both prey and their predators). Indeed, community ecology, particularly in the context of fisheries management and conservation, deserves much further attention, with behavioural effects potentially driving large-scale outcomes (Blumstein and Fernández-Juricic 2010). Our results appear to have implications for the effects of boats on alarm cue reactions in fishes, but we caution against making conclusions regarding boats specifically, as only a single boat was used in this study. Additional experiments should be conducted using several boat cues that encompass the range of noises that boats can produce. In situations where boat noise is shown to have negative impacts on fishes, it may be prudent to implement or modify regulations to minimize those impacts in biodiversity hot-spots or sensitive habitats. Approaches to reducing boat noise may include the implementation of quiet zones, speed restrictions, or the required use of mufflers or low-volume engine models (Haren 2007; Leaper and Renilson 2012; Würsig et al. 2000). Future study is needed to understand the need and effectiveness of variation in these approaches to noise management.

\section{Acknowledgements}

This research was funded by the Natural Science and Engineering Research Council of Canada to MCOF and DPC. We thank Reid Bryshun for operating the boat.

\section{References}

Blumstein DT, Fernández-Juricic E (2010) A Primer of Conservation Behavior. Sinauer Associates, Sunderland.

Bracciali C, Campobello D, Giacoma C, Sara G (2012) Effects of nautical traffic and noise on foraging patterns of Mediterranean damselfish (Chromis chromis). PloS One 7:e40582.

Bruintjes R, Radford AN (2013) Context-dependent impacts of anthropogenic noise on individual and social behaviour in a cooperatively breeding fish. Anim Behav 85:13431349.

Brumm H (2013) Animal communication and noise vol 2. Springer,

Chan A, Giraldo-Perez P, Smith S, Blumstein DT (2010) Anthropogenic noise affects risk assessment and attention: the distracted prey hypothesis. Biol Lett 6:458-461.

Chivers DP, Smith RJF (1993) The role of olfaction in chemosensory-based predator recognition in the fathead minnow, Pimephales promelas. J Chem Ecol 19:623-633.

Chivers DP, Smith RJF (1994) Fathead minnows, Pimephales promelas, acquire predator recognition when alarm substance is associated with the sight of unfamiliar fish. Anim Behav 48:597-605.

Chivers DP, Smith RJF (1995) Fathead minnows (Pimephales promelas) learn to recognize chemical stimuli from high-risk habitats by the presence of alarm substance. Behav Ecol 6:155-158. 
Cui B, Wu M, She X, Liu H (2012) Impulse noise exposure in rats causes cognitive deficits and changes in hippocampal neurotransmitter signaling and tau phosphorylation. Brain Res 1427:35-43.

Cunnington GM, Fahrig L (2010) Plasticity in the vocalizations of anurans in response to traffic noise. Acta Oecol 36:463-470.

Ferrari MCO, Sih A, Chivers DP (2009) The paradox of risk allocation: a review and prospectus. Anim Behav 78:579-585.

Ferrari MCO, Trowell JJ, Brown GE, Chivers DP (2005) The role of learning in the development of threat-sensitive predator avoidance by fathead minnows. Anim Behav 70:777-784.

Ferrari MCO, Wisenden BD, Chivers DP (2010) Chemical ecology of predator-prey interactions in aquatic ecosystems: a review and prospectus. Can J Zool 88:698-724.

Graham AL, Cooke SJ (2008) The effects of noise disturbance from various recreational boating activities common to inland waters on the cardiac physiology of a freshwater fish, the largemouth bass (Micropterus salmoides). Aquat Conserv 18:1315-1324.

Halfwerk W, Slabbekoorn H (2009) A behavioural mechanism explaining noise-dependent frequency use in urban birdsong. Anim Behav 78:1301-1307.

Halfwerk W, Slabbekoorn H (2015) Pollution going multimodal: the complex impact of the human-altered sensory environment on animal perception and performance. Biol Lett $11: 20141051$.

Haren AM (2007) Reducing noise pollution from commercial shipping in the Channel Islands National Marine Sanctuary: a case study in marine protected area management of underwater noise. J Int Wildlife Law Policy 10:153-173.

Helfman GS (1989) Threat-sensitive predator avoidance in damselfish-trumpetfish interactions. Behav Ecol Sociobiol 24:47-58.

Hildebrand JA (2009) Anthropogenic and natural sources of ambient noise in the ocean. Mar Ecol Prog Ser 395:5-20.

Kunc HP, Lyons GN, Sigwart JD, McLaughlin KE, Houghton JD (2014) Anthropogenic noise affects behavior across sensory modalities. Am Nat 184:E93-E100.

Leaper R, Renilson M (2012) A review of practical methods for reducing underwater noise pollution from large commercial vessels. Int J Marit Eng 154:A79-A88.

Lima SL, Dill LM (1990) Behavioral decisions made under the risk of predation - a review and prospectus. Can J Zool 68:619-640.

Mathis A, Crane AL (2017) Chemoreception. In: Call J (ed) APA Handbook of Comparative Psychology, vol 2. APA Books, Washington DC, pp 69-87.

McDonald MA, Hildebrand JA, Wiggins SM (2006) Increases in deep ocean ambient noise in the Northeast Pacific west of San Nicolas Island, California. J Acoust Soc Am 120:711718.

Morris-Drake A, Kern JM, Radford AN (2016) Cross-modal impacts of anthropogenic noise on information use. Curr Biol 26:R911-R912.

Northcutt RG (2006) Connections of the lateral and medial divisions of the goldfish telencephalic pallium. J Comp Neurol 494:903-943.

Olson CL (1976) On choosing a test statistic in multivariate analysis of variance. Psychol Bull 83:579.

Pijanowski BC, Farina A, Gage SH, Dumyahn SL, Krause BL (2011) What is soundscape ecology? An introduction and overview of an emerging new science. Landscape Ecol 26:1213-1232. 
Purser J, Radford AN (2011) Acoustic noise induces attention shifts and reduces foraging performance in three-spined sticklebacks (Gasterosteus aculeatus). PloS One 6:e17478.

Relyea RA (2002) Local population differences in phenotypic plasticity: Predator-induced changes in wood frog tadpoles. Ecol Monogr 72:77-93.

Rogers PH, Hawkins AD, Popper AN, Fay RR, Gray MD (2016) Parvulescu revisited: small tank acoustics for bioacousticians. In: The effects of noise on aquatic life II. Springer, pp 933941.

Sarà G et al. (2007) Effect of boat noise on the behaviour of bluefin tuna Thunnus thynnus in the Mediterranean Sea. Mar Ecol Prog Ser 331:243-253.

Scholik AR, Yan HY (2002) Effects of boat engine noise on the auditory sensitivity of the fathead minnow, Pimephales promelas. Environ Biol Fishes 63:203-209.

Sebastianutto L, Picciulin M, Costantini M, Ferrero EA (2011) How boat noise affects an ecologically crucial behaviour: the case of territoriality in Gobius cruentatus (Gobiidae). Environ Biol Fishes 92:207-215.

Shannon G et al. (2016) A synthesis of two decades of research documenting the effects of noise on wildlife. Biol Rev 91:982-1005.

Simpson SD, Purser J, Radford AN (2015) Anthropogenic noise compromises antipredator behaviour in European eels. Global Change Biol 21:586-593.

Simpson SD, Radford AN, Holles S, Ferarri MC, Chivers DP, McCormick MI, Meekan MG (2016a) Small-boat noise impacts natural settlement behavior of coral reef fish larvae. In: The Effects of Noise on Aquatic Life II. Springer, pp 1041-1048.

Simpson SD, Radford AN, Nedelec SL, Ferrari MC, Chivers DP, McCormick MI, Meekan MG (2016b) Anthropogenic noise increases fish mortality by predation. Nat Commun 7:10544.

Smith RJF (1992) Alarm signals in fishes. Rev Fish Biol Fisher 2:33-63.

Templeton CN, Zollinger SA, Brumm H (2016) Traffic noise drowns out great tit alarm calls. Curr Biol 26:R1173-R1174.

Voellmy IK, Purser J, Simpson SD, Radford AN (2014) Increased noise levels have different impacts on the anti-predator behaviour of two sympatric fish species. PloS One 9:e102946.

von Frisch K (1938) Zur psychologie des fisch-schwarmes. Naturwissenschaften 26:601-606.

Wisenden BD, Pogatshnik J, Gibson D, Bonacci L, Schumacher A, Willett A (2008) Sound the alarm: learned association of predation risk with novel auditory stimuli by fathead minnows (Pimephales promelas) and glowlight tetras (Hemigrammus erythrozonus) after single simultaneous pairings with conspecific chemical alarm cues. Environ Biol Fishes 81:141-147.

Würsig B, Greene C, Jefferson T (2000) Development of an air bubble curtain to reduce underwater noise of percussive piling. Mar Environ Res 49:79-93. 